\title{
A GESTÃO DO PATRIMÔNIO E A RESSIMBOLIZAÇÃO DE CÁRCERES
}

\section{TOMBADOS}

\author{
Ana Paula Barradas Maranhão \\ Henry Socrates Lavalle Sullasiii
}

iDiscente de Doutorado no Programa de Pós-graduação em Arqueologia da Universidade Federal de Pernambuco.

anapaula.maranhao@ufpe.br. https://orcid.org/0000-0001-5084-2239.

iiDocente do Dep. de Arqueologia da Universidade Federal de Pernambuco. henry.lavalle@ufpe.br. https://orcid.org/0000-0002-0690-6781

\begin{abstract}
Resumo: 0 objetivo deste trabalho é analisar o processo de patrimonialização de antigas casas de detenção e compreender o que implica sua transformação em instrumentos culturais e turísticos. Foram estudados três antigos presídios, dentre os quais, dois deles foram tombados no âmbito Federal pelo Iphan: a antiga Cadeia Eclesiástica (Aljube) localizada em Olinda/PE (atual Museu de Arte Contemporânea de Pernambuco), a Casa de Câmara e Cadeia em Pirenópolis/GO (atual Museu do Divino Espírito Santo) e a Casa de Detenção do Recife (atual Casa da Cultura de Pernambuco). Como procedimentos metodológicos foram realizados: entrevistas semiestruturadas; observação participante; e o levantamento de documentos oficiais e midiáticos, discutidos sob a perspectiva da antropologia do patrimônio e do turismo. A análise dos dados mostra pouca reflexividade memorial e cultural por parte dos entrevistados. Os resultados apontam que os cárceres em questão, sobrevivem pela sustentabilidade turística garantindo sua manutenção, porém em um âmbito mais econômico do que memorial.
\end{abstract}

Palavras-Chave: Patrimonialização; Monumentos históricos; Ressimbolização; Patrimônio cultural; Turismo; Memória.

Abstract: The objective of this work is to analyze the process of cultural heritage policies of former detention houses and understand what their transformation in cultural and tourist instruments. Three old prisons were studied: the "Cadeia Eclesiástica (Aljube)" located in Olinda/PE (current "Museu de Arte Contemporânea de Pernambuco"), The "Casa de Câmara e Cadeia" located in Pirenópolis/GO (current "Museu do Divino Espírito Santo") and the "Casa de detenção do Recife" (current "Casa da Cultura de Pernambuco"). As methodological procedures were carried out: semi-structured interviews; participant observation; and the survey of official and media documents, discussed under the perspective of the anthropology of heritage and tourism. The analysis of the data shows little memorial and cultural reflexivity on the part of the interviewees. The results show that the prisons in question survive for tourism sustainability, guaranteeing their maintenance, but in a more economical than memorial scope.

Key Words: Patrimonialization, Historical monuments, Resimbolization, Cultural Heritage, Tourism, Memory 


\section{Introdução}

A gestão do patrimônio cultural exige interdisciplinaridade e a participação de especialistas das diversas áreas, como história e história da arte, museologia, conservação e restauro, gestão turística, planejamento arquitetônico e urbanístico, entre outras. Neste contexto de interdisciplinaridade e gestão vários trabalhos estão sendo produzidos (Ribeiro, 2013; Toledo, 2018; Oosterbeeke e Lino2020; Campelo et. al. 2020; Libonati et. al. 2021; entre outros). Porém, só dois trabalhos abordam o processo de patrimonialização de cárceres, como é o caso de Maranhão e Aguiar (2014) que apresentam uma reflexão sobre o sistema prisional e a transformação de alguns desses locais em patrimônio cultural e o trabalho de Maranhão e Aguiar (2013) que ponderam acerca da história da patrimonialização, trazendo percepções conceituais sobre o tema.

Segundo a lista de bens Tombados e em processo de Tombamento, há um aumento na quantidade de antigos cárceres que são patrimonializados e que atualmente possuem novas utilizações. Os encarregados destes processos de tombamento são o Instituto do Patrimônio Histórico e Artístico Nacional - Iphan, e a Fundação do Patrimônio Histórico e Artístico de Pernambuco - Fundarpe, órgãos que possuem a competência de garantir legalmente a preservação dos bens de interesse cultural nos níveis nacional e estadual.

A investigação quanto à ressimbolização destas antigas casas de detenção, busca entender o processo desde sua patrimonialização, a sua transformação em equipamentos culturais e artísticos e as novas dinâmicas sociais ocasionadas. Não é comum a preocupação com a reutilização destes espaços como uma forma de repensar os novos papéis destas ambientações na sociedade. Ao parar para pensar o cárcere desativado em escala mundial, novas utilizações da arquitetura prisional vêm ocorrendo com sucesso, com uma concepção globalizada, onde parâmetros tradicionais são quebrados e novos discursos são constituídos a partir deste outro olhar.

A função do espaço penitenciário com novas utilizações, definitivamente, surge para acrescentar uma visão diferente e convida a refletir sobre o futuro destes espaços como ambientes de convívio, já que não se trata apenas de ajuizar sobre a utilização e relação entre os indivíduos e o ambiente, mas também o convívio social entre estes. 
Na concepção de François Laplantine (2005) é fundamental que se tenha com clareza, as características do universo urbano, as sensações e a razão. Ele recorda que "dos interesses de uma reflexão antropológica é tecer laços inéditos entre o sensível, o social e o político" (Laplantine, 2005, pp.151-152 apud Duarte e Villanova, 2013, p.9).

Por conseguinte, tornou-se essencial refletir sobre a importância desses espaços como guardiães de sua história, para que o bem patrimonial tenha a garantia de ser preservado não só como bem arquitetônico, mas como bem histórico-cultural em suas novas significações e suas implicações quanto ao processo memorial e de identificação coletiva.

Nesta perspectiva, o presente artigo tem por objetivo refletir e analisar o processo de patrimonialização de antigas casas de detenção, assim como, compreender o que implica sua transformação em instrumentos culturais e turísticos; através dos relatos das pessoas envolvidas direta ou indiretamente com estes bens patrimonializados; bem como, as determinações provindas de leis e disposições firmadas pelos órgãos governamentais em nível federal e estadual.

O critério para a escolha dos nossos objetos de estudo foi realizado pela esfera do tombamento: dois tombamentos federais e um estadual, que nos forneceu uma visão das realidades institucionacionais de cada órgão. No âmbito federal pelo IPHAN, tivemos a antiga Cadeia Eclesiástica - ALJUBE, localizada na cidade de Olinda, no Estado de Pernambuco (atual Museu de Arte Contemporânea de Pernambuco) e a Casa de Câmara e Cadeia de Pirenópolis no Estado de Goiás (atual Museu do Divino Espírito Santo). O terceiro, a Casa de Detenção do Recife (atual Casa da Cultura de Pernambuco) com tombamento na esfera estadual pela Fundarpe. Além da importância histórica e arquitetônica dos patrimônios carcerários.

\section{Os Processos de Patrimonialização e Tombamento}

O patrimônio cultural pode ser conceituado como "o conjunto de bens móveis e imóveis existentes no País e cuja conservação seja de interesse público, quer por sua vinculação a fatos memoráveis da história do Brasil, quer por seu excepcional valor arqueológico ou etnográfico, bibliográfico ou artístico" (Iphan, 2020b). Tem como características a heterogeneidade, o valor e os atributos culturalmente relevantes e representa uma fonte inesgotável no campo investigativo, nas mais diversas áreas de atuação. 
Sob a concepção do Serviço do Patrimônio Histórico e Artístico Nacional (atual Instituto do Patrimônio Histórico e Artístico Nacional), cuja função inicial era a criação de uma lei federal que regulamentasse a preservação do patrimônio nacional, foi aprovado em 1937 um decreto, até hoje em vigor, Decreto-Lei $n^{\circ} 25$ (Brasil, 1937). É através deste, que foi instituída a regulamentação do tombamento; já a carta de Veneza de 1964 (Iphan, 1964), relata o patrimônio como um elemento da expressão social refletida através de muitas formas e meios, tornando referência uma localidade.

O patrimônio material protegido pelo Iphan é composto por um conjunto de bens culturais classificados segundo sua natureza, conforme os quatro Livros do Tombo: arqueológico, paisagístico e etnográfico; histórico; belas artes; e das artes aplicadas. A Constituição Federal de 1988, em seus artigos 215 e 216, ampliou a noção de patrimônio cultural ao reconhecer a existência de bens culturais de natureza material e imaterial e, também, ao estabelecer outras formas de preservação - como o Registro e o Inventário - além do Tombamento, instituído pelo Decreto-Lei no 25, de 30 de novembro de 1937 que é adequado, principalmente, à proteção de edificações, paisagens e conjuntos históricos urbanos. Os bens tombados de natureza material podem ser imóveis como as cidades históricas, sítios arqueológicos e paisagísticos e bens individuais; ou móveis, como coleções arqueológicas, acervos museológicos, documentais, bibliográficos, arquivísticos, videográficos, fotográficos e cinematográficos (Iphan, 2020d).

Os bens culturais de natureza imaterial dizem respeito àquelas práticas e domínios da vida social que se manifestam em saberes, ofícios e modos de fazer; celebrações; formas de expressão cênicas, plásticas, musicais ou lúdicas; e nos lugares (como mercados, feiras e santuários que abrigam práticas culturais coletivas). [...] Para atender às determinações legais e criar instrumentos adequados ao reconhecimento e à preservação desses bens imateriais, o Iphan coordenou os estudos que resultaram na edição do Decreto no. 3.551, de 4 de agosto de 2000 - que instituiu o Registro de Bens Culturais de Natureza Imaterial e criou o Programa Nacional do Patrimônio Imaterial (PNPI) [..] (Iphan, 2020c).

Para a compreensão de toda a dinâmica simbólica que envolve a patrimonialização ${ }^{1}$ de um bem é fundamental o entendimento do processo de tombamento. Pode-se perceber o

\footnotetext{
1“A patrimonialização concede a este artefato uma nova vida e um novo valor. A partir da patrimonialização, ele deve ser preservado e exposto ao olhar do público, ou seja, ele se torna bem público e legado de um coletivo de indivíduos. Esta é uma
} 
tombamento como um processo simbólico da transformação de um lugar antes tido como "comum", mas que por sua história, edificação, paisagem, entre outros, desperta a necessidade de proteção para que o passado não seja apagado através da manutenção do bem material.

A patrimonialização perpassa pela ideia de que o processo de tombamento, o ato legislativo, visa à proteção de bens de interesse da nação, do estado ou município. Ao passar pela avaliação de um grupo de especialistas que fazem a análise técnica e designam ou não aquele com status de natureza singular, especial, proporcionada ao bem pelo tombamento, o diferenciando do contexto das outras construções tidas como "comuns".

Ao apresentar essa diferenciação, após processo de reconhecimento, o bem é inscrito como patrimônio material em um ou mais livros do tombo e após este ato jurídico está submetido a uma proteção com direitos, obrigações e restrições.

Podemos dizer que atrelado ao tombamento do bem, existem etapas comemorativas, ou seja, atos solenes que equivalem a reuniões formais ou celebrações mediante presença de pessoas com prestígio político e social da localidade (Kersten, 1998, p.48).

Em anuência com o pensamento de Arantes (2012), ao refletir sobre a nossa sociedade, sobressai a indústria e as políticas culturais oficiais "[...] padrões cognitivos, estéticos, éticos, produzidos por especialistas e de interesse da classe dominante são difundidos por toda sociedade" (Arantes, 2012, pp. 44-45).

Ao sofrer essa transformação, o bem é também recontextualizado socialmente, obtendo assim um novo significado e pertencendo ao passado e ao presente. Entende-se, assim, que o bem patrimonial não carrega em si mesmo, em sua essência, significados naturalmente emanados dele, mas se caracteriza por possibilitar que um conjunto de signos verbais e não-verbais, definidos historicamente, seja acionado para significar, através dele. Dado que os universos de representação são orientados em direção à realidade por meio de signos específicos, o mundo exterior torna-se significativo na interação social, materializando-se socialmente num processo de convenção. O bem patrimonial passa a simbolizar algo, alguma coisa, um fato, um ser (Kersten, 1998, p.48).

operação complexa que envolve diversos agentes especialmente treinados com a finalidade de uma construção especial de valor. Os bens patrimonializados são considerados sagrados para uma cultura ou um grupo social organizado." (Abreu, 2015, pp.67-68) 
Sendo assim, a Casa de Câmara e Cadeia de Pirenópolis foi desativada e por sua relevância arquitetônica, urbanística, paisagística e histórica passou a ser tombada em nível federal. Obtendo esta nova conotação social, um novo uso foi dado ao espaço com a implementação do Museu do Divino Espírito Santo. "Ocupando a seu modo esse monumento, os usuários o transformam simbolicamente, redefinindo as funções dos equipamentos existentes segundo suas próprias necessidades e concepções." (Arantes, 2012, p.49). Mediante o descrito, fica claro que o tombamento é um ato no qual a proteção e manutenção são procedimentos que tornam real a existência de um bem patrimonial.

\section{Metodologia e levantamento de dados}

Considerando os objetos de estudo, estes são três presídios, dois deles tombados no âmbito federal pelo Iphan, a antiga Cadeia Eclesiástica - ALJUBE localizada na cidade de Olinda, no Estado de Pernambuco (atual Museu de Arte Contemporânea de Pernambuco), ver (Figura 1) e a Casa de Câmara e Cadeia de Pirenópolis no Estado de Goiás (atual Museu do Divino Espírito Santo), ver (Figura 2). O terceiro, a Casa de Detenção do Recife (atual Casa da Cultura de Pernambuco), ver (Figura 3), tombada no âmbito estadual.
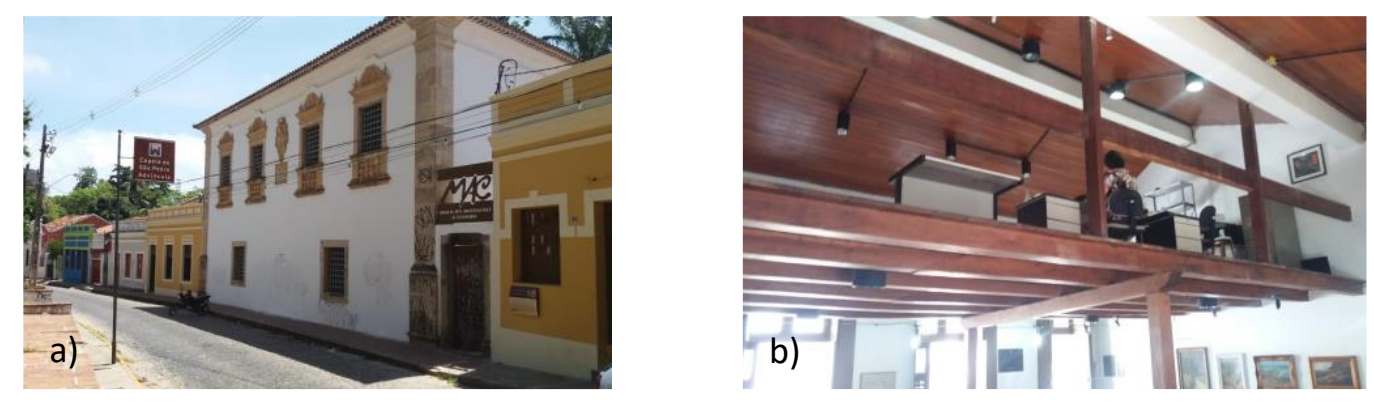

Figura 1: Museu de Arte Contemporânea de Pernambuco. a)Fachada e b) Administração.
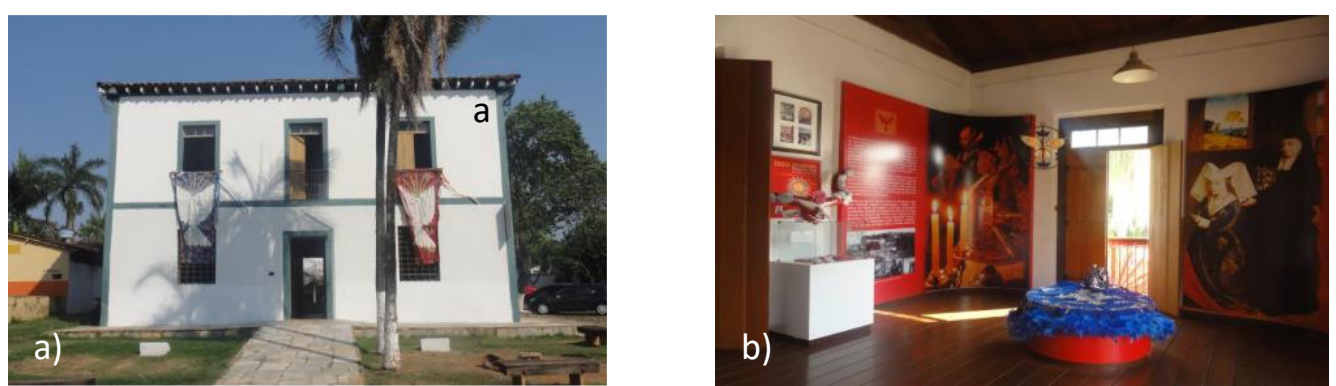

Figura 2: Museu do Divino Espírito Santo de Pirenópolis. a) Vista frontal e b) Exposição permanente. Fonte: Acervo pessoal, Maranhão (2017) 

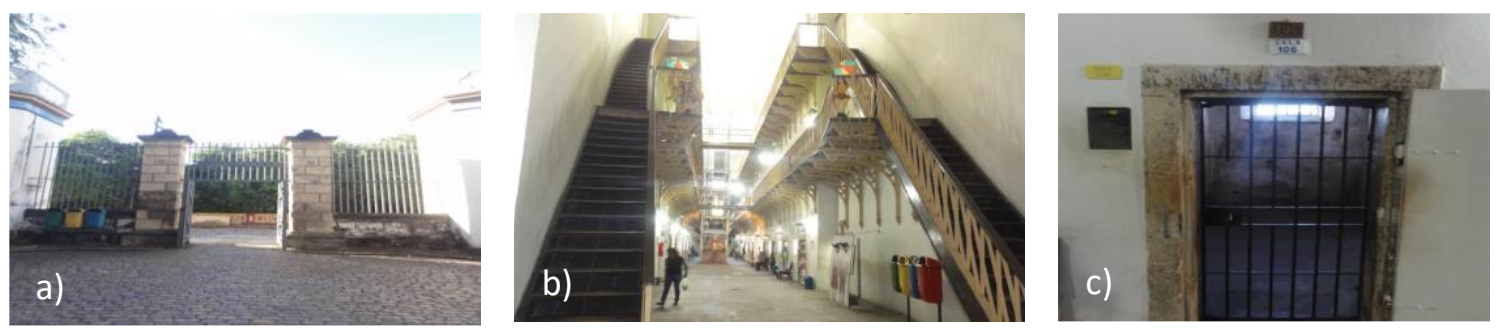

Figura 3. Casa da Cultura de Pernambuco. a) Entrada secundária da casa da cultura, b) Elevador e escadas e c) Cela "original". Fonte: Acervo pessoal, Maranhão (2017)

O método da pesquisa constituiu-se por trabalho de campo, que decorreu de forma exploratória e descritiva, foram utilizadas entrevistas semiestruturadas e conversas informais com os atores da pesquisa, além da observação participante. A preferência por este tipo de entrevista foi devido à necessidade da utilização de um roteiro predefinido, porém sem amarras, isto é, estava aberto às mudanças que se fizessem necessárias pelo entrevistador, no transcorrer da entrevista. A pesquisa abrangeu um centro cultural voltado para a venda de artesanato e dois museus. Portanto, o procedimento empregado nas entrevistas fora adaptado, de acordo com a realidade de cada local e integrada a observação participante como citado anteriormente; logo, de fundamental importância para a compreensão do objeto investigado, já que favoreceu um contato mais próximo com os atores.

A seleção dos atores envolvidos, automaticamente recaiu nas pessoas que estavam diretamente envolvidas na problemática elencada e que com base nos dados coletados no campo, puderam clarificar, através de suas práticas espaciais, aspectos ainda desconhecidos na reutilização desses cárceres, inclusive quanto aos enfoques sociais e culturais.

A identificação desses atores de uma maneira geral, incidiu sobre os gestores, visitantes/turistas, lojistas/ comerciantes e moradores das localidades. No Museu de Arte Contemporânea de Pernambuco, não houve condições para realização da pesquisa de campo nos mesmos moldes dos demais, pois, encontrava-se em restauro. Assim sendo, os atores foram a diretora e uma funcionária do bem patrimonial.

Os gestores segundo suas atribuições, eram os responsáveis por planejar, dirigir, monitorar e direcionar ações, de acordo com a perspectiva institucional do órgão. Assim, as entrevistas com os responsáveis pela gestão dos locais observados foram de grande valia, para que houvesse um confronto entre o que foi previsto pelos órgãos governamentais para uso do bem e como funcionava na prática. 
Dando continuidade ao processo ora descrito, realizamos o levantamento documental, executado na lista de bens tombados e em processos de tombamento do Instituto do Patrimônio Histórico e Artístico Nacional (IPHAN, 2016b) e também efetuamos uma investigação no Arquivo Noronha Santos (IPHAN, 2016a), que forneceu informações sobre o uso atual e a descrição dos Bens Tombados.

Em relação a abordagem teórica utilizada esta abrangeu as áreas do conhecimento como Antropologia, História, Arquitetura, Museologia e Turismo, para a delimitação do recorte em questão. Para a concepção clara e objetiva sobre a função social do espaço penitenciário devese a Cordeiro (2010) e Foucault (2012) com a explanação de fatores determinantes para o planejamento arquitetônico de uma prisão. Na obra "Antropologia e patrimônio cultural: diálogos e desafios contemporâneos", organizado por Lima Filho e Abreu (2007), encontramos referências das pesquisas desenvolvidas na esfera da Antropologia do Patrimônio. Em nível nacional e internacional, o debate científico em torno do intangível despontava como eixo central e com isso o estudo do patrimônio material sob o viés antropológico, segundo Lima Filho e Abreu (2007) ficava mais restrito as problemáticas em torno das relações entre a museologia e antropologia. Já a obra de Malinowski (1978), proporcionou uma visão teórica acerca dos métodos para coleta de dados etnográficos, como também, o cuidado que se deve ter no processo de investigação quanto à condução das conversas, meios de aproximação com os atores, o que favoreceu o fortalecimento do poder de articulação.

Em prosseguimento, foi realizada na Casa da Cultura de Pernambuco, no período de 02 a 25 de setembro de 2015, o início das atividades de campo com observação participante e dados obtidos in loco através de uma entrevista semiestruturada com o administrador do local, 15 (quinze) entrevistas semiestruturadas com visitantes e mais 15 entrevistas semiestruturadas no âmbito dos lojistas, além de conversas informais.

No Museu do Divino Espírito Santo de Pirenópolis em Goiás, como segundo campo de pesquisa, ocorreu no período de 28 de setembro a 05 de outubro de 2015 similarmente realizamos atividades de campo com observação participante e dados obtidos in loco através de uma entrevista semiestruturada com o Secretário Municipal de Cultura, Esporte, Lazer e Juventude da cidade, além de 07 (sete) entrevistas semiestruturadas com moradores e comerciantes e 03 (três) entrevistas semiestruturadas turistas que visitavam o museu, além de conversas informais. 
Quanto ao Museu de Arte Contemporânea de Pernambuco, terceiro campo de investigação não houve condições para realização da pesquisa de campo nos mesmos moldes, pois, encontrava-se em reforma. Desta forma foi realizada apenas uma entrevista semiestruturada com a diretora e outra com uma funcionária do bem patrimonial em 07 de dezembro de 2016.

A observação participante foi realizada durante todo o período do campo, sendo fundamental para a compreensão dos objetos investigados, já que favoreceu o contato mais próximo com os atores supracitados. A observação participante ao qual nos referimos é enquanto método de pesquisa etnográfica, que consiste na inserção do pesquisador na ambientação que se deseja estudar, para assim entender a situação em questão, observar e participar para compreender melhor. Apresentamos como autor referencial Malinowski (1978) e sua obra Os Argonautas do Pacífico Ocidental.

A Patrimonialização e o Processo de Ressignificação: A Casa da Cultura de Pernambuco, o Museu do Divino Espírito Santo e o Museu de Arte Contemporânea de Olinda

A antiga Casa de Detenção do Recife, foi inaugurada no dia 25 de abril de 1855, é considerada uma das edificações mais tradicionais do Recife do século XIX. Encontra-se localizada entre a Estação Ferroviária do Recife e a Ponte 6 de março. O projeto original é de autoria do engenheiro e urbanista José Mamede Alves Ferreira, responsável por outras obras na cidade, como o Hospital Pedro II e o Ginásio Pernambucano. Seguindo o modelo mais moderno das penitenciárias da época, o panóptico de Bentham² (Fundarpe, 2017).

Após funcionar por 118 anos como presídio, em 1973 o então governador Eraldo Gueiros Leite determinou o fechamento da Casa de Detenção do Recife. A Casa da Cultura de Pernambuco foi inaugurada em 14 de abril de 1976 e conta com cento e dez lojas de artesanatos (produtos em couro, barro, pedras, comidas típicas nordestinas, bordados, entre outros). A modificação da antiga Casa de Detenção do Recife para um centro cultural foi sugerida pelo artista plástico Francisco Brennand com o intuito de promover um espaço dedicado às artes na cidade. "[...] Convidados por Brennand, a arquiteta ítalo-brasileira Lina Bo Bardi e o arquiteto Jorge Martins

\footnotetext{
2 o panóptico é um edifício estruturado para ter um ponto de observação central, que permite a um único vigilante observar todos os prisioneiros, sem que estes possam saber se estão ou não sendo observados. O medo leva ao comportamento desejado (Foucault, 2012).
} 
Júnior foram os responsáveis pela elaboração do projeto de renovação e adequação do edifício" (Fundarpe, 2017).

Conforme o relato histórico, a nova significação da edificação ocorreu antes do processo de tombamento, porquanto, foi reconhecida como bem patrimonial apenas em 1980. Após a patrimonialização desse bem e da nova significação de uso, indagamos: a Casa da Cultura de Pernambuco atuava de forma compatível com sua vigente missão, como equipamento cultural? A sua utilização estava restrita apenas às atividades turísticas com primazia para a venda de artesanato e não como centro de difusão cultural? Havia uma preocupação dos órgãos competentes quanto à preservação do seu patrimônio arquitetônico? O que teria impossibilitado o funcionamento no espaço físico desse bem patrimonial de ações inerentes ao encargo a que se destinava?

O Gestor da Casa Sr. Luiz Carlos Silva descreveu a Casa da Cultura de Pernambuco como:

“Eu descrevo a Casa da Cultura como um equipamento cultural muito importante, não só para Recife, mas para todo Pernambuco. Por ter diversos elos de ligações com todo o Estado de Pernambuco, em respeito ao artesanato. Todo o Estado de Pernambuco vem pra cá fazer a oferta de artesanato para o público recifense e de fora também". (Silva, set. 2015).

Vários lojistas explicitaram de modo espontâneo que a Casa da Cultura de Pernambuco era um lugar esquecido pelo poder público e que ela precisava de uma maior divulgação, para que o público frequentador não se resumisse meramente a turistas e que seria muito bom estimular a frequência do recifense no local. "A cultura representa a identidade de um povo, que deve ser transmitida de geração para geração. É algo que tem que se preservar e mostrar para os mais jovens que não conheceram antes." (Entrevista com proprietário de loja A da ala norte, sep. 2015). ${ }^{3}$

É um ponto turístico e precisa receber mais visitantes. Deveria ser mais divulgado e ter mais atrações turísticas, não só quando há navios. A Fundarpe deveria ter iniciativa para fazer as coisas, que só acontecem quando os lojistas pedem. (Entrevista com vendedora de loja B da ala sul na Casa da Cultura de Pernambuco, sep. 2015).

\footnotetext{
${ }^{3}$ Foi mantido o anonimato de todos os entrevistados, exceto dos gestores dos objetos da pesquisa.
} 
"A situação aqui é complicada. Tem que trabalhar na divulgação que nem existe. Aqui só tem burocracia por pertencer a um órgão público que nada faz. A infraestrutura é uma vergonha." (Entrevista com proprietária de loja $\mathrm{C}$ da ala norte na Casa da Cultura de Pernambuco, sep. 2015).

“Para quem mora aqui isso tudo não é nada. Para turistas, eles se encantam. Desde o presídio até a cultura. O patrimônio histórico é que deveria ser mais divulgado" (Entrevista com proprietário de loja D da ala sul na Casa da Cultura de Pernambuco, sep. 2015).

No que tange as entrevistas e conversas informais com visitantes e/ou turistas, a maioria possuía a faixa etária de 20 a 40 anos e apresentavam alto grau de escolaridade, com no mínimo ensino superior completo. No caso dos turistas a maioria chegou à cidade por transporte aéreo, visitavam a Casa da Cultura de Pernambuco por intermédio de amigos e/ou parentes e em segundo lugar pelo através de guias de turismo. Em relação ao motivo da viagem, quando turistas, a maioria veio a lazer e visitavam o Recife pela primeira vez. Este dado contribuiu para reforçar o que já havia sido observado: o contato com o bem por todos pesquisados foi pela primeira vez. Durante a coleta de dados, foi perceptível que os turistas conheciam pouco sobre a cidade do Recife, muitos estavam hospedados em Porto de Galinhas e só passavam o dia na capital e se sabiam que o local era tombado, a maioria disse que sim, porém, não conseguiam aprofundar o assunto.

“Não conhecíamos o local. Queríamos comprar algumas lembrancinhas e a recepcionista do hotel que estamos hospedadas nos indicou a Casa da Cultura. Ela falou que o local era seguro e abriria às $08 \mathrm{~h}$, mas descobrimos que só abre às 09h. Então fomos conhecer melhor o local." (Entrevista com turista gaúcha, na Casa da Cultura de Pernambuco sep. 2015).

Quanto à qualificação do atrativo e em relação à segurança, limpeza, acessibilidade, variedade das lojas e qualidade das mercadorias, foi classificado como "bom", mas, o que deixava a desejar era o serviço de informações turísticas considerado "regular".

Portanto, inserimos uma pequena amostra das entrevistas e mediante a análise dos dados, ficou nítida a falta de comprometimento do poder público com a história da Casa de Detenção do Recife. De acordo com as respostas emanadas pela representação governamental através da entrevista com o administrador do local, a percepção da Fundarpe em relação ao bem era bastante equivocada. Na sua concepção tudo funcionava perfeitamente e sem necessidade de modificações, porquanto a antiga Casa de Detenção do Recife estava bem representada 
enquanto memória coletiva do recifense. Percebesse uma política cultural por meio de ideologias estatais, que possuía um discurso pronto, porém que não se mostrava condizente com a realidade.

Em relação "A Casa de Câmara e Cadeia de Pirenópolis foi erguida em 1733, sendo a primeira cadeia do Estado de Goiás, tendo sido construída em terreno situado na esquina da rua do Rosário com a atual Neco Mendonça, dando frente para a Igreja Matriz" (Carvalho, 2011, p. 60). A Casa de Câmara e Cadeia foi demolida e reconstruída em outra área da cidade.

A cadeia em seu local atual foi construída em um terreno que fazia parte do antigo Largo do Hospício, no período de 1916 a 1919, idêntica à anterior. Em estilo colonial, foi edificada próximo à ponte sobre o rio das Almas por Cristovam José de Oliveira. O prédio tem dois pavimentos: na parte superior funcionava a Câmara de Vereadores e na parte térrea o policiamento local e cadeia. (Carvalho, 2011, p. 60).

A Casa de Câmara e Cadeia de Pirenópolis seguiu a estrutura arquitetônica mais corriqueira no Brasil na época. O modelo prisional era a cadeia pública que dividia a mesma edificação de dois pavimentos com a Câmara Municipal (cadeia no térreo e câmara no primeiro pavimento), comumente chamado de casa de câmara e cadeia.

Em 27 de março de 2007, houve a solenidade de entrega da restauração da Casa de Câmara e Cadeia de Pirenópolis. O Iphan executou a obra de revitalização da casa, já adaptada com acesso para deficientes e organizou a mostra de abertura. A Prefeitura de Pirenópolis ficou responsável pela gestão do espaço e a Agência Goiana de Cultura Pedro Ludovico (Agepel) se comprometeu a montar no local o Museu de Imprensa do Estado de Goiás (Iphan, 2015).

O Museu do Divino Espírito Santo foi inaugurado no dia 07 de outubro de 2009, em menção aos 282 aniversários da fundação da cidade de Pirenópolis em Goiás. O museu abrigava peças relativas à Festa do Divino Espírito Santo, uma das mais populares do Estado. Festa de repercussão internacional que era mostrada ao público visitante, através de suas peças, fotografias, textos e vídeo, como também pela transmissão de sua história e simbologia. Fazendo com que essa edificação tombada pelo Iphan, se tornasse um museu, concebido com o intento de possibilitar aos turistas que frequentam o município durante todo o ano, conhecer o evento por intermédio de um acervo representativo. 
Constituída por vários rituais religiosos e expressões culturais, a Festa do Divino é uma celebração profundamente enraizada no cotidiano dos moradores de Pirenópolis e determinante dos padrões de sociabilidade local; ela se realiza nesta cidade a cada ano, desde 1819, durante cerca de 60 dias, com clímax no Domingo de Pentecostes, cinquenta dias após a Páscoa, relata o site do (Iphan, 2020a).

Segundo o então Secretário Municipal de Cultura, Esporte, Lazer e Juventude, Sr. João Luiz Teixeira Brandão, o foco principal das atividades turísticas da localidade concentrava-se na visitação ao museu, cujo público frequentador em sua maioria eram turistas nacionais e locais. Questionado se existia alguma prática cultural no local além do próprio museu: "Não. Às vezes [...] muito raramente a gente faz algumas exposições. Só quando as exposições são de complexidade menor e voltada também a algo mais próximo a festa ou ao patrimônio." (Brandão, out. 2015).

Questionado se os moradores faziam alguma relação com o fato do Museu do Divino Espírito Santo existir em um antigo cárcere, o entrevistado respondeu que não. Que hoje virou uma casa cultural mesmo, patrimônio cultural. Deixou aquele "ranço" de presídio. "É que a nova geração não vivenciou o local sendo presídio, então o tempo vai passando e o local é visto como um patrimônio. Até o turista vem mais pela questão cultural", relata.

Qual a necessidade da patrimonialização?

Eu acho fundamental para uma cidade histórica. Se não houvesse, eu acho que muitas coisas teriam sido destruídas. Eu acho que aqui ainda demorou a vir. Acho que deveria ter sido mais cedo. Eu moro em uma casa no centro histórico e nós estamos fazendo um restauro na casa agora. A gente tem todo cuidado, faz questão de gastar um pouco a mais. É algo que meu bisavô fez, meu vô cuidou, agora meu pai tá passando pra mim. Mas ainda existe gente que não aceita, tem gente que odeia o Iphan aqui, só falta tacar pedra. Eu acho que se não fosse o Iphan não tinha essa preservação, essa cultura, a gente não teria essa riqueza não (Brandão, out. 2015).

O Museu do Divino era propagado pelo site da Prefeitura e pelos guias de informações turísticas. No caso dos turistas, o meio de transporte utilizado para chegarem à localidade foi o 
automóvel (carros particulares), visto que eram de cidades circunvizinhas. A faixa etária entre eles variou de 30 a 50 anos e em relação ao motivo da viagem, foram a cidade à lazer. ) ${ }^{4}$

Quase que por unanimidade os visitantes estavam bastante satisfeitos com o local: "O museu tem uma bela arquitetura e conta de forma resumida a história da Festa do Divino Espírito Santo da cidade. Adorei! assisti a um filme sobre a origem da festa, e me senti como se estivesse lá." (Conversa informal com turista A no Museu do Divino Espírito Santo, out.2015). "O museu traz toda a história das Festas do Divino da região. O casarão também é belo. Vale a visita." (Conversa informal com turista B no Museu do Divino Espírito Santo, out.2015). Com exceção de um deles, que alegou ter gostado do museu, mas questionou a falta de informações históricas sobre o local: "O prédio é legal, mas na minha opinião não explica bem sua história." (Conversa informal com turista C no Museu do Divino Espírito Santo, out.2015).

Contudo, nas conversas com os moradores e comerciantes foi perceptível, que existia uma clara divisão quanto à insatisfação de alguns no que dizia respeito à ausência de uma penitenciária que atendesse aos interesses da comunidade e a opinião de outros que se mostraram suscetíveis a transformação do prédio existente em museu.

Já a edificação projetada para abrigar o Aljube da Diocese de Olinda e Recife, planejada em 1722, pelos engenheiros João de Macedo Corte Real e Diogo da Silveira Velozo foi finalizado para o cumprimento de sua função em 1765. Era a única prisão eclesiástica que se tem notícias no Brasil, durante todo o período da Inquisição. "Sua função era o aprisionamento de homens e mulheres acusados de infrações contra a Igreja Católica Apostólica Romana" (MAC, 2020).

A casa do Aljube "após o fim da inquisição até o ano de 1950, passou a ser a Cadeia Pública de Olinda. Atualmente, o prédio da antiga cadeia abriga o Museu de Arte Contemporânea de Pernambuco." (Mac, 2020).

Em relação ao Museu de Arte Contemporânea de Pernambuco (Mac), inaugurado em 23 de dezembro de 1966, com a doação de parte da Coleção do Embaixador Assis Chateaubriand ao Estado de Pernambuco. O Mac integrava o conjunto de edificações da Fundação do Patrimônio Histórico e Artístico de Pernambuco (Fundarpe), voltados para o lazer e cultura no centro histórico da cidade de Olinda, a citar: "além da sede, fazem parte do seu Complexo Cultural a

\footnotetext{
${ }^{4}$ Foi mantido o anonimato de todos os entrevistados, exceto dos gestores dos objetos da pesquisa.
} 
Capela de São Pedro Advíncula, a Praça Assis Chateaubriand (ambas em frente à sua sede), a Casa da Reserva Técnica e a Galeria de Arte Tereza Costa Rêgo." (Mac, 2020).

Sendo o referido museu um dos instrumentos culturais selecionados para fazer parte deste estudo, porém este não seguiu o mesmo direcionamento dado aos outros, porque estava em restauro. Assim sendo, a pesquisa de campo não pôde ser feita em sua totalidade, o que nos levou a manter essa edificação como um dos objetos de estudo, foi a sua extrema relevância histórica (única prisão eclesiástica no Brasil), mas estávamos cientes da impossibilidade da permanecia metodológica utilizada nas outras ambientações. Portanto, contamos apenas com a entrevista da sua diretora e uma funcionária, já que a casa da administração do MAC encontrava-se aberta ao público.

Quanto à descrição e foco de atuação do museu, a diretora Sra. Célia Labanca se referiu a sua história, além do seu rico acervo com mais de 4.000 obras entre esculturas, arte fotográfica, artes plásticas, que foram sendo constituídos ao longo dos anos, estando nelas incluída a coleção doada pelo Embaixador Assis Chateaubriand ao Estado. Enfatizou que se o local não fosse um prédio tombado e munido de tanta historicidade, provavelmente já teria sido destruído.

No decorrer da entrevista foi citado que a exposição temporária sobre a coleção de Assis Chateaubriand na casa da administração teve a finalidade de manter o fluxo de visitantes ativo, mesmo que muito reduzido, enquanto perdurasse o processo de reforma. "Não tem condições financeiras, é uma luta diária para continuar e preservar toda a herança histórica.", relata (Labanca, dez.2016).

O museu já foi uma grande efervescência, movimento artístico em termos de artes plásticas. Lançando excelentes artistas plásticos com notoriedade mundial e que inclusive seus trabalhos fazem parte do nosso acervo. Mas infelizmente a coisa vai esfriando. A cultura hoje em dia não é nada. Os museus são as casas dos artistas e isso tem que ser preservado (Labanca, dez.2016).

A diretora complementou que a percepção de que no local funcionava uma casa de detenção era visível pelas chaves, dobradiças, grades, material e o tipo de tijolos utilizados na construção. A transformação de um antigo presídio em espaço cultural: "É uma grande ideia. Se não se faz a transição, a história se perde. Isso aqui é um monumento e o que vai ser feito com um prédio como este? Eu acho o máximo." (Labanca, dez.2016). 
O Mac assim como a Casa da Cultura de Pernambuco era um espaço cultural do governo do Estado, "Os turistas quando vêm ao museu eles já sabem que aqui foi um presídio e que agora é um museu," afirmou a diretora.

Portanto, a partir dos dados coletados e através das informações fornecidas pela diretora do museu, ficou evidente que a utilização do bem para atividades turísticas tornou-se vital, para a sua manutenção. Servia como medida protetiva para que ele não fosse destruído pela ausência de ocupação do espaço. Resultado este, que corrobora com as práticas utilizadas nas antigas casas de detenções patrimonializadas em questão.

\section{Reflexões sobre a gestão patrimonial brasileira: o Caso do Museu de Arte Contemporânea de Pernambuco, o Museu do Divino Espírito Santo e a Casa da Cultura de Pernambuco}

Ao ponderar sobre o patrimônio cultural brasileiro e sua forma de gestão, através dos três objetos de estudo, fica evidente por meio da fala dos entrevistados e da observação participante, que é necessária uma gestão patrimonial realmente eficaz, e que a sociedade tenha verdadeiramente a sensação de pertença com seus bens culturais e estes sejam preservados por este grupo.

Todos os bens aqui pesquisados, nas suas ressimbolizações, voltavam-se para a "cultura", tendo como "carro-chefe" o turismo, aquele que mais traria rentabilidade, sendo que, um deles era centro cultural e os outros dois museus.

Em todos os objetos investigados, o público frequentador era essencialmente composto por turistas. Por parte das gestões locais, este, constituía-se como fator positivo pelo fato de necessitarem de visitantes para manterem os espaços abertos e justificarem sua existência. Todavia, os locais não eram utilizados pelos seus moradores; quer dizer, pelos recifenses, olindenses nem pirenopolinos.

No caso da gestão do patrimônio cultural relacionado ao desenvolvimento socioeconômico através do turismo, é visto como o salvador pelo seu poder de desenvolvimento econômico, mas nenhuma avaliação é feita sobre os efeitos danosos da atividade.

Em relação à gestão do patrimônio cultural pertinente a educação patrimonial, memória e identidade, apresentamos o exemplo da Casa da Cultura de Pernambuco. Como um centro cultural que tinha a missão de comercialização de artesanato e o desenvolvimento de 
atividades ligadas à música, literatura, gastronomia regional, teatro e manifestações culturais e na realidade limitavam-se quase que exclusivamente a venda de peças artesanais; ao passo que, as demais atividades não foram vistas durante a pesquisa de campo, portanto, presumese não serem rotineiras, mas sim de caráter assistemático.

Ademais fora criada para uso da população local "inclusive com a finalidade de divulgar a cultura pernambucana para toda a sociedade" conforme seu resumo histórico e mantinha um público que em sua maioria era de visitação turística. Em contraposição, foi citado pelo seu administrador que o instrumento cultural era considerado como de grande importância não só para a cidade do Recife como para todo o Estado, em razão de favorecer uma ligação entre os municípios pernambucanos por intermédio da oferta do artesanato. Porém, no dia a dia, observou-se que Casa da Cultura de Pernambuco não fazia parte da rotina de lazer e uso do recifense. Como a pesquisa abrangeu também os finais de semana, verificou-se que, os presentes no espaço não tinham como motivo a diversão/lazer em seu tempo de ócio. E por estarem acompanhando alguém da família ou amigo "turista", para que estes fizessem compras. Portanto, não existia por parte deles nenhum vínculo, tão pouco identificação com o local.

O Museu de Arte Contemporânea de Pernambuco (Mac), assim como a Casa da Cultura de Pernambuco formam em conjunto com outros espaços, a rede de equipamentos culturais da Fundação do Patrimônio Histórico e Artístico de Pernambuco, tais como: Museu de Arte Sacra de Pernambuco (Maspe), Museu Regional de Olinda (Mureo), Cinema São Luiz, Museu do Estado de Pernambuco (Mepe), Museu do Barro de Caruaru (Mubac) e a Galeria do Centro de Artesanato de Pernambuco.

Os pernambucanos que visitavam o museu eram poucos e o público presente em quase sua totalidade era de turistas, como expôs a sua diretora; ou seja, assim como em todos os objetos da pesquisa, mais uma vez essas antigas construções não faziam parte da rotina de visitação e lazer dos moradores, uma vez que, enquanto não houver a adoção de medidas que façam com que esses bens patrimoniais sejam parte integrante da sociedade, tenderão ao aniquilamento.

Quanto aos bens patrimoniais supracitados em sua função primária de cárcere, tanto o centro cultural como os museus não divulgavam o passado enquanto casas de detenções. A conscientização da necessidade da preservação do patrimônio contribuirá sem dúvida, para que as futuras gerações possam conhecer e fazer uso dessa herança cultural, passando a sentir 
através das testemunhas do passado, o envolvimento dessas pessoas com a identificação da realidade histórica. Como preservar o que é indiferente ou até mesmo desconhecido? "Na falta dessa intenção de memória os lugares de memória serão lugares de história." (Nora, 1993, p.22). Diante das alegações citadas, a educação patrimonial, desponta como um poderoso instrumento como recurso para facilitar o encontro do indivíduo com seu passado, ou seja, com a sua identidade. Os primeiros envolvidos serão os habitantes da localidade e do entorno imediato.

A partir da reflexão acerca da eficácia na prática do uso desta política de preservação traçada pelos órgãos de proteção ao patrimônio, no caso o IPHAN e a FUNDARPE, concluiu-se que as comunidades não eram envolvidas na escolha do seu passado representativo, o que aumentava ainda mais o abismo entre elas e os espaços patrimonializados, pela inexistência da identidade.

Tendo em vista a gestão do patrimônio cultural em alusão a museologia, de acordo com o Instituto Brasileiro de Museus (Ibram, 2014) e conforme percebido através da pesquisa de campo, apenas uma pequena parte da população local conhecia e utilizava os museus e centros culturais como uma atividade de lazer, em seu momento de ócio. "Os museus têm como desafio melhorar a comunicação e a aproximação com moradores, primeiramente, para permitir o direito ao lazer e à cultura da sua comunidade, mas também para tê-los como parceiros e construtores do patrimônio que guardam e exibem." (Ibram, 2014, pp. 53-54).

Os museus, embora apresentassem acervos de inestimável valor artístico e cultural, ficavam em duas cidades consideradas como de porte populacional médio e pequeno como é o caso de Olinda e Pirenópolis respectivamente, cuja pessoas ou grupos que os procuravam eram seletos nas suas preferências. As riquezas culturais deles advindas tornaram-se incalculáveis, quer seja por meio da exposição de artes contemporâneas ou a exemplo de simples peças que representavam a fé, a memória e a identificação do povo pirenopolino, praticados anualmente por meio de um evento popular religioso.

Por conseguinte, a gestão do patrimônio cultural remissivo a disposições governamentais como medida protetiva, sabe-se que a administração dos bens pesquisados estava sob a responsabilidade de órgãos governamentais, entre os quais dois estaduais e um municipal. A antiga Casa de Detenção do Recife foi fechada exclusivamente com o intuito de retirar os presos do centro da cidade pelo seu crescimento urbano, não comportando mais na época, 
este serviço público no local. Foram removidos os detentos e como já havia a ideia de transformá-lo em centro cultural, foi feito um projeto para sua implementação em dois anos; já na Casa de Câmara e Cadeia de Pirenópolis, que consistia num espaço ocioso e a concepção do museu fora idealizada para que ao longo de todo o ano os turistas pudessem conhecer a festa do Divino Espírito Santo; do mesmo modo, o Aljube, passou a ser a Cadeia Pública de Olinda e posteriormente o Museu de Arte Contemporânea de Pernambuco, que também se efetivou para ocupação do patrimônio em desuso, quando houve a doação de parte do acervo do embaixador Assis Chateaubriand ao Estado de Pernambuco.

Sendo assim, em função das falas dos gestores, os espaços foram utilizados como uma maneira de ocupação do bem. Porquanto, com exceção do gestor da Casa da Cultura de Pernambuco, a posição do restante foi a de que, se as edificações patrimonializadas não recebessem novos usos, tenderiam a se transformar em ruínas e provavelmente chegariam a ser destruídas. Os mesmos eram localizados em três cidades diferentes, e em duas regiões do Brasil, entre elas o Nordeste e o Centro-Oeste e a realidade constatada foi à mesma. Mudaram apenas ínfimas considerações, porque na essência e na questão estrutural, não existiu diferenças consistentes.

Deste modo, a emissão de medidas institucionais para utilização de espaços patrimonializados inativos, eram empregadas para evitar a sua futura destruição e que o público frequentador desses ambientes, majoritariamente eram turistas. Responsáveis deste modo, por manter de forma sistemática o fluxo de visitação e assim garantir sua sobrevivência estrutural.

\section{Considerações Finais}

Ao longo do presente artigo foram contextualizadas realidades de forma analítica sobre as experiências de campo, entre os anos de 2015 à 2017, distribuídos entre os três antigos cárceres situados nos estados de Pernambuco e Goiás.

Á medida que se reproduz o papel que deveria ser desempenhado por esses bens após suas novas significações e coloca-os frente a uma realidade confirmada pela prática, chega-se a vislumbrar lacunas quanto a sua utilização. Em respeito aos três antigos cárceres, enquanto parte integrante de um processo memorial e de identificação coletiva, decorrentes das implicações sucedidas de suas transformações em instrumentos culturais e turísticos. 
Todos os bens investigados voltavam-se para a "cultura", tendo como "carro principal" o turismo, aquele que mais traria proveito econômico. A frente deles estava órgãos governamentais, estadual e municipal, que mantinham todo o controle de suas administrações. O destino de cada um dos bens foi delimitado de acordo com os interesses destes órgãos.

Ao analisar as estratégias e diretrizes da gestão patrimonial brasileira, tendo como base de dados as reflexões elaboradas nos casos supracitados fica evidente uma gestão ineficaz respaldada por políticas públicas definidas.

É fundamental que os conceitos de preservação sejam postos em prática e se a (re)utilização como museus e centros culturais é a mais viável para conservação e garantia física do bem, que assim seja feito, porém o seu significado social não pode ser omitido de um trabalho efetivo de conscientização e fortalecimento do sentimento de identificação da sociedade, com os citados bens patrimoniais. É notório que as questões imateriais e de memória não vem sendo consideradas como prioritárias pelas autoridades competentes.

Isto posto, e estando estes patrimônios entregues as decisões suscetíveis a atos políticos, consequentemente tornou-se evidente que os processos memoriais e de identidade coletiva, engajadas na ressimbolização desses remotos espaços, pendem ao esquecimento.

Não haverá nenhum patrimônio ressimbolizado, sem que haja uma clara definição no cumprimento dos seus preceitos e que neles estejam incluídos o trabalho com os moradores a exemplo da educação patrimonial. Existe a necessidade de mudanças para que a prática seja compatível com a proposta de atuação desses bens.

Resta convir, que enquanto perdurar a ineficiência das instituições governamentais responsáveis pela patrimonialização e delegação dos usos dessas construções históricas quanto ao cumprimento de suas reais atribuições e mobilização da comunidade, continuarão as mesmas ainda em processo de ressimbolização.Com isto, se quer dizer que este procedimento deverá ser constante, pois a qualquer momento pode haver mudanças devido à ressimbolização requerer uma releitura do passado, e que no presente pode trazer novas ressignificações.

\section{Agradecimentos}


O presente trabalho foi realizado com apoio da Coordenação de Aperfeiçoamento de Pessoal de Nível Superior - Brasil (CAPES), na forma de bolsa de Doutorado Pleno no País para Ana Paula Barradas Maranhão.

\section{Referências}

ABREU, R. 2015. Patrimonialização das diferenças e os novos sujeitos de direito coletivo no Brasil. In: Tardy, C., Dodebei, V. Memória e novos patrimônios, OpenEdition Press. 67-93

ARANTES, A. A. (2012). O que é cultura popular. Brasiliense, São Paulo.

BARRADAS MARANHÃO, A. P., BRANDÃO AGUIAR, S.M. 2013. Análise do processo histórico de patrimonialização e concepções sobre patrimônio. Revista do Memorial do Tribunal de Justiça de Sergipe. n. 1, 197-213.

BARRADAS MARANHÃO, A. P., Brandão Aguiar, S.M. 2014. Introdução ao sistema prisional e a patrimonialização da Casa da Cultura de Pernambuco. Revista Eletrônica do Programa de PósGraduação em Museologia e Patrimônio. v. 1, n. 1, 79-91.

BRANDÃO SOBRINHO, J. L. Entrevista no Museu do Divino Espirito Santo [out. 2015]. Entrevistadora Ana Paula Barradas Maranhão. Entrevista realizada no Museu do Divino Espirito Santo. Pirenópolis, GO.

BRASIL. Instituto Brasileiro de Museus. 2014. Museu e Turismo: estratégias de cooperação. Brasília, IBRAM.

BRASIL. Instituto do Patrimônio Histórico e Artístico Nacional. 2015. Restauro na Casa de Câmara e cadeia de Pirenópolis. Disponível em <http://portal.iphan.gov.br/noticias/detalhes/1791/iphanentrega-obras-de-restauro-da-casa-de-camara-e-cadeia-de-pirenopolis-go $>$ Acesso em: 11.Set.2015.

BRASIL. Instituto do Patrimônio Histórico e Artístico Nacional. 2016a. Arquivo Noronha Santos/IPHAN. Disponível em < http://portal.iphan.gov.br/ans/ > Acesso em: 25.Fev.2016 e 03.Jul.2017.

BRASIL. Instituto do Patrimônio Histórico e Artístico Nacional. 2016b. Bens Tombados e Processos de Tombamento em Andamento. Disponível em<http://portal.iphan.gov.br/uploads/ckfinder/arquivos/Lista_de_bens_tombados_2016.pdf> Acesso em: 03.Jul.2017.

BRASIL. Instituto do Patrimônio Histórico e Artístico Nacional. 1964. Carta de Veneza de maio de $1964 . \quad$ Disponível em http://portal.iphan.gov.br/uploads/ckfinder/arquivos/Carta\%20de\%20Veneza\%201964.pdf> Acesso em: 04. mai.2020.

BRASIL. Instituto do Patrimônio Histórico e Artístico Nacional. 2020a. Festa do divino Espírito Santo de Pirenópolis. Disponível em <http://portal.jphan.gov.br/pagina/detalhes/72> Acesso em 13.Mai.2020. 
BRASIL. Instituto do Patrimônio Histórico e Artístico Nacional. 2020b. Patrimônio Cultural. Disponível em <http://portal.iphan.gov.br/pagina/detalhes/218> Acesso em: 04.Mai.2020.

BRASIL. Instituto do Patrimônio Histórico e Artístico Nacional. 2020c. Patrimônio Imaterial. Disponível em <http://portal.iphan.gov.br/pagina/detalhes/234> Acesso em: 04.Mai.2020.

BRASIL. Instituto do Patrimônio Histórico e Artístico Nacional. 2020d. Patrimônio Material. Disponível em <http://portal.iphan.gov.br/pagina/detalhes/276> Acesso em: 04.Mai.2020.

BRASIL. Presidência da República. 1937. Decreto-Lei no 25, de 30 de novembro de 1937. Disponível em <http://www.planalto.gov.br/ccivil_03/decreto-lei/Del0025.htm> Acesso em: 04.mai.2020.

CAMPELO DOS SANTOS, A. L.; BARRADAS MARANHÃO, A. P.; LAVALLE SULLASI, H. S.; PEREGRINO TORRES RAMOS, A. C. NUVIS-UFPE: uma proposta inovadora de extroversão da reserva técnica associada ao laboratório LACOR-UFPE. Revista de Arqueologia, v. 33, n. 3, p. 330-35.

CARVALHO, A. 2011 Pirenópolis, coletânea 1727-2010: Histórias \& curiosidades. Pirenópolis, Livro Digital.

CORDEIRO, S. 2010. Até quando faremos relicários: a função social do espaço penitenciário. Maceió, EDUFAL.

DUARTE, C., VILLANOVA, R. 2013. Olhares sobre o lugar In: Novos olhares sobre o lugar: ferramentas e métodos, da arquitetura à antropologia. Contra Capa, FAPERJ, Rio de Janeiro.

FOUCAULT, M. 2012. Vigiar e Punir: nascimento da prisão. 40 ed. Vozes, Petrópolis, RJ.

LIMA FILHO, M., Abreu, R. 2007. A antropologia e o patrimônio cultural no Brasil. In: Lima Filho, M., Erket, C., Beltrão, J., (Org). Antropologia e patrimônio cultural: diálogos e desafios contemporâneos. Blumenau, Nova Letra.

KERSTEN, M. 1998. Os rituais de tombamento e a escrita da história: bens tombados no Paraná entre 1934-1937. (Tese de Doutorado), Universidade Federal do Paraná, Curitiba.

LABANCA, C. Entrevista MAC [dez. 2016]. Entrevistadora Ana Paula Barradas Maranhão. Entrevista realizada na administração do MAC. Olinda, PE.

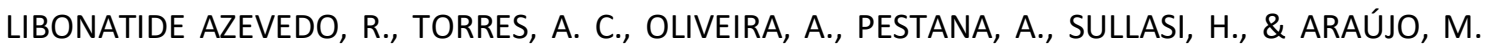
2021. Proposta de diagnóstico de conservação para acervos arqueológicos - um protocolo para a reserva técnica do LACOR/UFPE. Vestígios -Revista Latino-Americana de Arqueologia Histórica, 14(2), 101-120.

MALINOWSKI, B. 1978. Argonautas do pacífico ocidental. Abril Cultural, São Paulo.

PERNAMBUCO. Fundação do Patrimônio Histórico e Artístico de Pernambuco. (2017). Casa da Cultura de Pernambuco. Disponível em $<$ http://www.cultura.pe.gov.br/pagina/espacosculturais/casa-da-cultura/> Acesso em: 10. Set.2017.

PERNAMBUCO. Museu de Arte Contemporânea de Pernambuco. (2020). Museu de arte contemporânea de Pernambuco. Disponível 
em<http://www.cultura.pe.gov.br/pagina/espacosculturais/museu-de-arte-contemporanea-mac/> Acesso em: 13. mai.2020

NORA, P. 1993. Entre memória e história: a problemática dos lugares. Projeto História.PUC-SP, n. 10, São Paulo.

OOSTERBEEK, L.; LINO, J. T. 2020. Gestão do patrimônio arqueológico do Museu de Arte Préhistórica de Mação, Portugal. Revista de Arqueologia, v. 33, n. 3, 226-241.

RIBEIRO, D. L. 2013. A Musealização da Arqueologia: um estudo dos Museus de Arqueologia doXingó e do Sambaqui de Joinville. Tese (Doutorado em Arqueologia) - Universidade de São Paulo, São Paulo.

SILVA, L. C. Entrevista na Casa da Cultura de Pernambuco. [set. 2015]. Entrevistadora Ana Paula Barradas Maranhão. Entrevista realizada na Casa da Cultura de Pernambuco. Recife, PE.

TOLEDO, G. T. 2018. Musealização da Arqueologia e Conservação Arqueológica: experiências e perspectivas para a preservação patrimonial. Tese (Doutorado em Arqueologia) - Museu de Arqueologia e Etnologia, Universidade de São Paulo, São Paulo, 2018. 